\title{
Proposta de um sistema microcontrolado para aquisição de dados e automação de ambientes residenciais
}

\begin{abstract}
This article aims to present a proposal of microcontrolled system for data acquisition and automation of residential environments. The system developed aims to improve existing residential automation systems through the integration of residential appliances, allowing them to have different requirements such as safety, convenience and energy efficiency in a single application, aiming at the less redundancy of the electronic devices present in the user's home . In addition, there was a concern to use more popular technologies, such as Raspberry Pi, an expansion card and a mobile device with the Android platform, in order to provide a system with lower cost.

Resumo: Este artigo tem o objetivo apresentar uma proposta de sistema microcontrolado para aquisição de dados e automação de ambientes residenciais. O sistema desenvolvido tem como objetivo aprimorar os Sistemas de Automação Residencial existentes, através da integração dos aparelhos residenciais, permitindo-os ter diferentes requisitos como segurança, comodidade e eficiência energética em uma única aplicação, visando a menor redundância dos aparelhos eletrônicos presentes na casa do usuário. Ademais, houve uma preocupação em utilizar tecnologias mais populares, como o Raspberry Pi, uma placa de expansão e um dispositivo móvel com a plataforma Android, a fim de proporcionar um sistema com menor custo.
\end{abstract}

Keywords: Residential Environments; Home Automation; Raspberry Pi; Android; Integration. Palavras-chaves: Ambientes Residenciais; Automação Residencial; Raspberry Pi; Android; Integração.

\section{INTRODUÇÃO}

Nos últimos anos a tecnologia está cada vez mais evoluindo e presente na vida das pessoas. A sua disponibilidade e uso possibilita a construção de diversos sistemas que permitem automatizar o desenvolvimento de determinadas atividades cotidianas dos cidadãos que anteriormente eram executadas somente de forma presencial e que demandava uma maior parcela de tempo. Dessa forma, a automação tornou-se mais atrativa hoje em dia S. Folea e D. Bordencea (2012).

Em 1984, a Associação Nacional de Construtores de Casas (ANCC) introduziu o conceito de casa inteligente e permitiu a criação do ramo de automação residencial. As pesquisas e desenvolvimentos neste campo continuaram ao longo dos anos, sendo que anteriormente a automação estava mais restrita ao campo industrial e predial. Nesse caso, a automação residencial refere-se a introdução de tecnologia na residência com o objetivo de aumentar a qualidade de vida dos seus ocupantes, através do fornecimento de diferentes serviços como entretenimento, eficiência energética, comodidade, dentre outros. Ademais, esta tecnologia permite o gerenciamento de diferentes recursos residenciais de forma automática, remota e eficiente, o que possibilita a disponibilização de sistemas que satisfaçam necessidades de conforto, segurança e comunicação S. Folea e D. Bordencea (2012).

Em um Sistema de Automação Residencial (SAR) há um conjunto de dispositivos interconectados para controlar diversas funções em uma residência D. Sunehra (2015). Esse controle pode ser feito de forma remota ou local a depender do projeto desejado. Com isso, o usuário do sistema, mesmo distante de casa, pode verificar o status de seus aparelhos residenciais e programar ações para o seu retorno. Isso é possível devido ao avanço e popularização das tecnologias de aquisição de dados (sensores) e da comunicação sem fio, sendo que uma grande quantidade de sistemas adotam o ZigBee, Bluetooth, Wi-Fi e Global System Messaging (GSM) como tecnologias para troca de dados e sinalização entre os componentes, o que permite aos sistemas terem uma maior escalabidade e flexibilidade D. Sunehra (2015).

Desse modo, busca-se com essa pesquisa aprimorar os Sistemas de Automação Residencial existentes, através da integração dos aparelhos residenciais, permitindo-os ter diferentes requisitos como segurança, comodidade e eficiência energética em uma única aplicação, buscando a menor redundância dos aparelhos eletrônicos presentes na casa do usuário. Isso será possível a partir do desenvolvimento e disponibilização de uma central responsável por gerir todos os equipamentos domésticos de forma integrada, de modo a reduzir a quantidade de aparelhos eletrônicos que desempenham o mesmo papel com outros diferentes dispositivos domésticos. Adicionalmente, deseja-se oferecer uma maior segurança nas residências ao possibilitar o usuário do SAR monitorar o vazamento de Gás Liquefeito de Petróleo (GLP) e fumaça, sendo que será feito um alerta local e remoto sobre o vazamento de gás e fumaça, além da possibilidade de visualização do ambiente. Com isso, espera-se aumentar a adoção dos SAR, reduzir os custos com energia elétrica e consequentemente proporcionar uma melhor gerência e segurança do ambiente doméstico. 
O presente artigo é composto por cinco capítulos. O primeiro, apresenta uma introdução do projeto proposto. O segundo, apresenta os trabalhos relacionados com o tema principal. O terceiro, apresenta a metodologia e o desenvolvimento utilizado para a obtenção dos resultados. O quarto, apresenta os resultados obtidos a partir do desenvolvimento da pesquisa. Por fim, o último apresenta as considerações finais acerca do projeto desenvolvido.

\section{TRABALHOS RELACIONADOS}

Diversos trabalhos com diferentes características, aplicações e tecnologias foram desenvolvidos na área de Automação Residencial ao longo do tempo. Nesse sentido, ao propor o desenvolvimento do sistema apresentado neste artigo, foi feito um estudo sobre os diferentes sistemas implementados que possuem objetivos similares, a fim de identificar possibilidades de contribuição.

S. Folea e D. Bordencea (2012) desenvolveram um SAR com o objetivo de reduzir o consumo de energia através do uso de dispositivos $W i-F i$ de baixa potência. Nesse caso, o sistema permite o gerenciamento da iluminação, temperatura e segurança do ambiente residencial. Com isso, o usuário pode, por exemplo, ter conhecimento sobre a ocorrência de uma abertura brusca das janelas e configurar a temperatura desejada numa sala. Salienta-se que a detecção de incêndio é realizada com base somente no sensor de fumaça, sendo que não há nenhuma relação com o sensor de temperatura, além da ausência de um alerta remoto ao identificar um vazamento de gás no ambiente.

O. Bingol (2014) implementou um sistema que possibilita a gerência da segurança, iluminação e temperatura da casa de forma remota ou local. Nesse caso, o sistema desenvolvido realiza, no módulo de segurança, um alerta ao usuário caso ocorra um vazamento de gás, contudo o controle remoto do sistema não é realizado através de um aplicativo para dispositivo móvel.

Batistelo (2014) desenvolveu um protótipo de automação residencial com o uso do Raspberry Pi e Android. Nesse caso, o sistema permite ao usuário controlar remotamente sua residência através do aplicativo instalado em um dispositivo móvel com plataforma Android. Com isso, o usuário tem a liberdade de enviar comandos para controlar iluminação, equipamentos eletrônicos e o sistema de alarme. Contudo, o referido SAR possui sua lógica de processamento baseada no controle On/Off, ou seja, não há utilização de uma técnica de controle mais complexa, como uma máquina de estados ou aprendizado de máquina. Ademais, foi feito o uso somente de sensores com fio, sendo que não possibilita o aproveitamento de sensores mais modernos.

Azni et al. (2016) também implementaram um SAR que é gerenciado remotamente através de um aplicativo Android instalado em um celular. O sistema permite o controle das luzes, aparelho de ar condicionado e portas, fato que pode proporcionar uma economia de energia, pois o usuário pode desligar, por exemplo, a luz da sala e ar condicionado mesmo que ele tenha saído da casa e esquecido de realizar a referida ação. Porém, não há a presença de sensores no ambiente residencial, o que dificulta o conhecimento do atual estado do ambiente em que o sistema está instalado.
Também, não foi implementada uma técnica de controle automático, tornando o sistema limitado, pois o mesmo não executa ações de forma automática. Com isso, o SAR torna-se dependente do usuário para realizar suas ações.

\section{METODOLOGIA E DESENVOLVIMENTO}

Neste capítulo serão apresentados os procedimentos realizados para a obtenção dos resultados do projeto desenvolvido.

\subsection{Projeto do sistema}

No início do desenvolvimento do Sistema de Automação Residencial proposto foi feito o seu projeto, sendo que o mesmo contempla todas as suas partes, como a escolha de sensores e atuadores, definição do protótipo de residência, construção da lógica do sistema, desenvolvimento do aplicativo mobile e implantação do sistema.

Definição da residência e prototipagem Com o objetivo de conferir um perfil mais realista ao projeto e possibilitar o transporte do SAR para diferentes locais, foi decidido que o sistema desenvolvido seria implantando em um protótipo de residência com grande semelhança com uma casa concreta. A partir da análise de diferentes tipos de protótipos residenciais, foi adquirido um modelo em Medium Density Fiberboard (MDF). Nesse caso, ele possui dois pavimentos e oito cômodos, sendo dois banheiros, dois quartos, duas salas, uma cozinha e uma área de serviço.

Levantamento dos equipamentos residenciais e sensores No início da construção do SAR foi feita a escolha dos equipamentos residenciais controlados e os sensores. Nesse caso, tal atividade é fundamental para o desenvolvimento do sistema, pois impacta diretamente no seu projeto e nos serviços disponibilizados para os usuários. Em relação às influências no projeto, a tarefa supracitada indica ao desenvolvedor os limites de distância entre os dispostitivos eletrônicos (alarme, sensor de presença, dentre outros), a disposição deles na residência, o tipo de sinal compreendido (analógico, digital), o meio de transmissão (Rádio Frequência, fio, etc) e ângulo de cobertura, entre outros. No tocante aos requisitos disponíveis para os usuários, os equipamentos selecionados refletem diretamente na disponibilidade de diferentes requisitos como segurança, comodidade e eficiência energética.

Ao realizar um estudo sobre diversos equipamentos eletrônicos presentes em sistemas já desenvolvidos e sites de fabricantes, por exemplo, o da Intelbras, foi feita uma lista de diferentes dispositivos (sensores e equipamentos residenciais) e seus possíveis impactos no projeto. A partir disso, foi realizada a escolha dos dispositivos de acordo com características como disponibilidade no mercado, velocidade de processamento, custo, limites de tensão e corrente, entre outras.

Os sensores e equipamentos residenciais escolhidos podem ser verificados nas Tabelas 2 e 3 .

Definição dos circuitos A definição dos circuitos do sistema foi feita de acordo com os requisitos a serem oferecidos para os usuários, sendo que cada circuito tem um conjunto de sensores que captam o estado do ambiente 
Tabela 1. Sensores do sistema

\begin{tabular}{|c|c|}
\hline \multicolumn{1}{|c|}{ Sensores } & Função \\
\hline Sensor DHT22 & Medir temperatura e humidade \\
\hline Sensor de presença IVP 2000 & Detectar presença \\
\hline Sensor MQ-2 & Detectar vazamento de gás e fumaça \\
\hline Sensor XAS 4000 & Detectar abertura de porta ou janela \\
\hline Sensor crepuscular & Detectar a intensidade da iluminação \\
\hline
\end{tabular}

Tabela 2. Fonte: Silva Filho e Gertrudes (2019)

Tabela 3. Equipamentos do sistema

\begin{tabular}{|c|c|}
\hline Equipamento & Função \\
\hline Ar condicionado & Regulação da temperatura \\
\hline Som & Execur playlist do usuário \\
\hline Alarme & Aviso sobre intrusão e vazamento de gás \\
\hline Controle remoto & Entrada no sistema \\
\hline Câmera & Visualizar a residência \\
\hline Lâmpada & Iluminação \\
\hline Computador & Acesso ao sistema pelo usuário \\
\hline
\end{tabular}

Fonte: Próprio autor

em que estão inseridos e geram valores que são utilizados como dados de entrada no sistema. Nesse caso, os sinais gerados pelos sensores são usados para tomada de decisão na unidade de controle. Além disso, acionam um conjunto de saídas de acordo com as entradas utilizadas. Os circuitos definidos no sistema são: comodidade, segurança e eficiência energética.

O circuito de segurança é subdivido em circuito de intrusão, incêndio e controle de acesso. O circuito de intrusão é formado pelos sensores de abertura presente na sala localizada no térreo, câmera localizada na sala do $1^{\circ}$ andar, além dos sensores de presença colocados na garagem e sala do térreo. Nesse caso, o referido circuito possui a função de informar ao sistema a ocorrência de uma invasão na casa através da detecção de presença pelo sensor, sendo que em caso positivo um alarme será ativado e o usuário será avisado. Já o circuito de incêndio é formado pelo sensor de presença, e de gás (GLP) e fumaça, os quais estão presentes na cozinha. Vale salientar que o sensor de presença fixado na cozinha é associado com o sensor de gás, pois o primeiro verifica a presença de alguma pessoa no cômodo para que seja enviada uma mensagem de alerta para o usuário de forma remota, sendo que o alarme local é disparado independentemente da presença de pessoas. Por fim, o circuito de controle de acesso é formado pela fechadura eletrônica que é simulada via aplicativo mobile.

Já o circuito de comodidade é formado pelo sensores de temperatura e umidade presentes na parte superior da residência. Nesse caso, eles foram instalados no referido local, pois ficam próximos ao elemento central de controle (Raspberry Pi). Vale ressaltar que pode ser feita uma associação entre a temperatura e umidade para um eventual acionamento de um sistema de irrigação do jardim, possibilitando um melhor cuidado para plantas. Ademais, o presente circuito é formado por todos os botões presentes no aplicativo mobile, os quais possibilitam o usuário controlar os equipamentos de forma remota.

Por fim, o circuito de eficiência energética tem a função de evitar o desperdício de energia. Ele é formado pelos sensores de presença localizados na sala 1, quarto 1 e garagem, além do sensor crepuscular. Nesse caso, os sensores de presença foram associados aos crepusculares para que haja o acionamento das lâmpadas do recinto na presença pessoas e que a luminosidade esteja ausente, fato que permite diminuir o consumo de energia. Vale ressaltar que, devido a utilização do pino digital do módulo do sensor crepuscular, o mesmo indica somente a presença ou não de luz no ambiente, sendo que a sensibilidade é configurada através do potenciômetro presente no módulo utilizado. Os sensores de presença localizados na sala 1 e garagem informam a central o momento em que é necessário disparar o temporizador, sendo que esse determinará o tempo que a luz ficará ligada.

\subsection{Definição do Módulo da Unidade de Controle}

Nessa etapa foi iniciado o desenvolvimento da Unidade de Controle de acordo com a arquitetura apresentada na Figura 1, a qual é baseada no modelo proposto por Castro (2009). Nesse caso, ela é formada pelos módulos de aquisição de dados, processamento e entrada/saída. A Unidade de Controle desenvolvida é responsável por realizar a comunicação com os sensores instalados na residência, receber e enviar sinais para as aplicações do usuário, além de enviar sinais de controle para os equipamentos residenciais.

Figura 1. Arquitetura do sistema

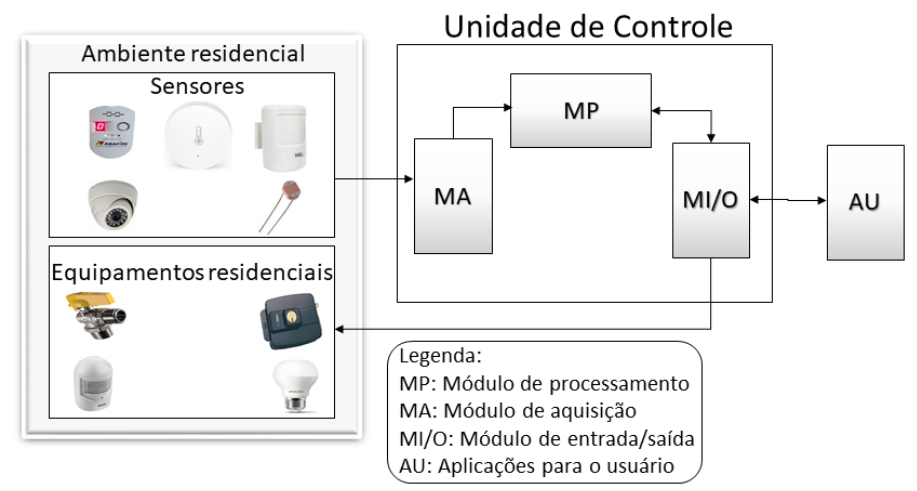

Fonte: Silva Filho e Gertrudes (2019)

\subsection{Definição do Módulo de aquisição de dados}

Ao ter conhecimento sobre todos os equipamentos residenciais selecionados e as características dos sinais emitidos/recebidos por eles, foram escolhidas as tecnologias responsáveis por realizar a aquisição dos dados dos dispositivos instalados na residência e envio para o módulo de processamento. Essa atividade foi desempenhada com base na revisão bibliográfica realizada acerca das tecnologias de aquisição de dados mais utilizadas nos projetos existentes e de acordo com os sinais emitidos pelos dispositivos que compõem o SAR.

Aquisição de dados Essa etapa é fundamental para o funcionamento do sistema, pois é nela que ocorre a obtenção dos sinais oriundos dos sensores e programas do usuário. Nesse caso, eles são utilizados como entrada do sistema e processados pelo Módulo de Processamento (MP), o qual é constituído pelo dipositivo de controle Raspberry Pi 3 modelo B. 
Nesse sentido, com base nos meios de comunicação utilizados pelos sensores presentes no sistema foram selecionadas as formas de aquisição de dados, sendo escolhidas a por fio, Radio Frequência e USB. Para a utilização da comunicação sem fio via $\mathrm{RF}$, foi feito o uso do receptor $M X-05 \mathrm{~V}$, o qual opera na frequência de $433 M H z$. Ele possui quatro pinos, nos quais os dois mais internos são para dados (RXDATA) e o restante para o terra $(G N D)$ e alimentação $(V C C)$ de 5 Volts. Com isso, são utilizados três pinos do Raspberry $P i$ ( $V C C, G N D$ e entrada digital) para fazer a ligação com o módulo receptor. Vale salientar que a utilização do receptor $M X-05 \mathrm{~V}$ permitiu a obtenção dos sinais dos sensores de presença, abertura e do controle remoto.

A aquisição dos dados dos sensores de luminosidade (LDR), gás, temperatura e umidade foi feita com o uso de fios, sendo que eles foram conectados diretamente aos pinos do Raspberry Pi. Para realizar o uso do sensor digital DHT22 foram utilizados 3 pinos, sendo um de dados, outro de $G N D$ e o último de alimentação. A fim de obter os valores de temperatura, foi feito o uso da biblioteca DHT22 da Adafruit, sendo que disponibiliza a função Adafruit $\mathrm{DHT}_{-}$read retry(sensor, pino sensor) que retorna o valor da temperatura e umidade.

A detecção da presença ou não de fumaça e gás (GLP, metano, butano) no ambiente foi feita através do sensor MQ-2, sendo que foram utilizados os pinos de alimentação (5 Volts), GND e o digital de dados.

A identificação da presença ou não de luz no ambiente foi feita através do Módulo Sensor de Luminosidade Fotossensitivo, sendo que o mesmo é composto por um sensor fotocélula LDR (Resistor Dependente de Luz), responsável pela variação da resistência conforme a intensidade da luminosidade incide sobre ele. Para o seu correto funcionamento, deve-se realizar o uso dos três pinos disponíveis (dados, alimentação e terra).

A aquisição da imagem capturada pela câmera foi possível através da utilização da porta $U S B$ do Raspberry $P i$. Nesse caso, foi utilizada uma Webcam com saída $U S B$ e essa foi conectada diretamente ao dispositivo de controle. Vale ressaltar que para a aquisição dos dados da Webcam, foi necessário o uso do pacote fswebcam, o qual permite a visualização da imagem do ambiente e também a configuração de parâmetros como a resolução, por exemplo.

Finalmente, para realizar a conexão entre o Raspberry $P i$ e a caixa de som foi utilizado o módulo Bluethooth já implementado no dispositivo de controle. Com isso, o usuário pode escutar o arquivo de aúdio selecionado.

\subsection{Definição do Módulo de processamento de dados}

De posse dos equipamentos responsáveis por efetuar a aquisição de dados, foi realizada a escolha do dispositivo eletrônico de controle, sendo que o Raspberry P $i 3$ modelo B (ver Figura 2) foi selecionado. Nesse caso, tal tarefa foi feita de acordo com a pesquisa realizada acerca dos dispositivos de controle utilizados em diferentes projetos e requisitos de velocidade de processamento, quantidade de memória, pinos de entrada/saída, suporte a tecnologias Wireless e Bluethooth, linguagem de programação suportada, dentre outros. De acordo com o manual do fabricante, o Raspberry $P i 3$ modelo B possui $1 G B$ de
RAM LPDDR2, processador Broadcom BCM2837 (quatro núcleos rodando a $1,2 \mathrm{GHz}$ ), chip gráfico VideoCore IV (400 MHz), suporte a conectividade Bluetooth 4.1 e Wi-Fi 802.11n, 4x portas USB 2.0, entrada para cartão microSD, porta Ethernet, sáida de áudio e HDMI. Portanto, é um dispositivo compacto, completo e que contempla as necessidades do projeto.

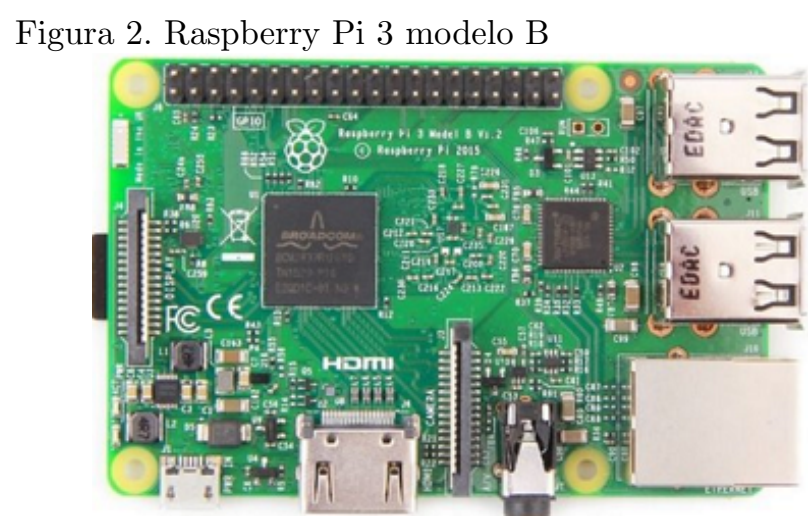

Fonte: Silva Filho e Gertrudes (2019)

\subsection{Projeto da Lógica do Sistema}

Para iniciar o projeto da lógica do sistema, foi feito, primeiramente, um estudo sobre diferentes estratégias de implementação como Máquina de Estados, Mineração de dados, controle On/Off, entre outras. Nesse caso, a estratégia de Mineração de Dados, conforme a revisão bibliográfica realizada, é mais utilizada em sistemas de recomendação, ou seja, sugerem ações para os usuários realizarem. Já o controle On/Off não é adequado ao projeto, pois torna o sistema com perfil mais manual. Portanto, foi decidido a implementação de uma Máquina de Estados de Mealy, sendo que o estado futuro do sistema depende do estado atual e valores das entradas. Tal estratégia permite que sejam realizadas ações manuais pelo usuário e automáticas pelo sistema. A Máquina de Estados projetada foi implementada no Raspberry $P i$ através da utilização da linguagem Python 3 no software IDLE 3.\%.

Definição dos Estados do Sistema Para definir os estados do sistema, primeiramente, foi feita uma análise das entradas do sistema (comandos e valores dos sensores), a fim de verificar possíveis comportamentos do SAR diante das mudanças de tais valores. Para facilitar a visualização e análise de todas as possibilidades de valores de entrada, prontamente, foi feita uma tabela verdade para cada Máquina de Estados do sistema (incêndio, comodidade, eficiência energética e intrusão).

A tabela da Máquina de Estados de Comodidade (ver Tabela 4) apresenta somente duas entradas de comando, sendo representadas pelos botões de visualizar a imagem capturada pela câmera (Cam) e o responsável pelo acionamento da fechadura eletrônica (Bt_fech). Ao analisar a variação de todas as possibilidades de valores das entradas, constatou-se a necessidade da criação de quatro estados, sendo denominados como Stand-by, ver_cam (ver câmera), abre_fech (abre fechadura) e fech_cam (ver câmera e abre fechadura). Como pode-se observar, os estados supracitados refletem as ações que serão efetuadas pelo SAR de 
acordo com as entradas oriundas do aplicativo mobile e o estado atual. Portanto, se o usuário, por exemplo, pressionar o botão responsável por abrir a fechadura eletrônica, a máquina de estados irá gerar um sinal de saída que será responsável por destravá-la. Ademais, a Tabela 4 também apresenta a transição entre os estados através das colunas estado atual e estado futuro, sendo que foram utilizados 2 bits para representá-los. Com isso, é possível saber qual será o próximo estado a depender do estado atual e o valor das entradas de comando.

Tabela 4. Tabela da Máquina de Comodidade

\begin{tabular}{c|c|c|c|c|c|c|c|c|c|}
\hline \multicolumn{2}{c|}{ Entrada } & \multicolumn{2}{c|}{ Estado atual } & \multicolumn{2}{c|}{ Próximo estado } & \multicolumn{3}{c|}{ Saida/ ações } \\
\hline Bt_fech & CAM & Q1 & Q0 & Q1 $^{*}$ & Q0* & Stand_by & ver_cam & abre_fech fech_cam \\
\hline 0 & 0 & 0 & 0 & 0 & 0 & 1 & 0 & 0 & 0 \\
\hline 0 & 1 & 0 & 0 & 0 & 1 & 0 & 1 & 0 & 0 \\
\hline 1 & 0 & 0 & 0 & 1 & 0 & 0 & 0 & 1 & 0 \\
\hline 1 & 1 & 0 & 0 & 1 & 1 & 0 & 0 & 0 & 1 \\
\hline 0 & 0 & 0 & 1 & 0 & 0 & 1 & 0 & 0 & 0 \\
\hline 0 & 1 & 0 & 1 & 0 & 1 & 0 & 1 & 0 & 0 \\
\hline 1 & 0 & 0 & 1 & 1 & 0 & 0 & 0 & 1 & 0 \\
\hline 1 & 1 & 0 & 1 & 1 & 1 & 0 & 0 & 0 & 1 \\
\hline 0 & 0 & 1 & 0 & 0 & 0 & 1 & 0 & 0 & 0 \\
\hline 0 & 1 & 1 & 0 & 0 & 1 & 0 & 1 & 0 & 0 \\
\hline 1 & 0 & 1 & 0 & 1 & 0 & 0 & 0 & 1 & 0 \\
\hline 1 & 1 & 1 & 0 & 1 & 1 & 0 & 0 & 0 & 1 \\
\hline 0 & 0 & 1 & 1 & 0 & 0 & 1 & 0 & 0 & 0 \\
\hline 0 & 1 & 1 & 1 & 0 & 1 & 0 & 1 & 0 & 0 \\
\hline 1 & 0 & 1 & 1 & 1 & 0 & 0 & 0 & 1 & 0 \\
\hline 1 & 1 & 1 & 1 & 1 & 1 & 0 & 0 & 0 & 1 \\
\hline
\end{tabular}

Fonte: Silva Filho e Gertrudes (2019)

A tabela da Máquina de Estados de Incêndio possui uma entrada de comando, a qual é representada pelo botão modo de segurança (Seg) do aplicativo Android, além de duas de sensores presentes na cozinha, sendo o sensor de gás Gas_c e o de presença (Pres_c). Ao variar os valores das entradas de forma a criar diferentes possibilidades de contexto, observou-se a necessidade da criação de três estados, sendo denominados como Stand-by, alarme, além de alarme e e-mail. O estado denominado estado alarme só é ativado quando o modo de segurança está ligado e o sensor detecta a presença de gás. Ademais, o estado alarme e e-mail somente é ativado com as condições supracitadas e a ausência de pessoas na cozinha. Salienta-se que a supracitada Máquina de Estados realiza somente um alerta ao detectar o vazamento de gás, sendo não foi projetado nenhum processo de mitigação, pois pode provocar alguma faísca e consequentemente um incêndio na residência. Por fim, a Máquina de Estados de Incêndio contempla a transição entre os três estados existentes, sendo que foram utilizados 2 bits para representá-los.

A tabela da Máquina de Estados Intrusão possui cinco entradas ao total, sendo duas entradas de comando que são representadas pelos botões modo de segurança (Seg) e modo de economia (Efic) do aplicativo mobile, além das três relacionadas aos sensores de presença instalado na garagem $\left(\mathrm{P} \_\mathrm{g}\right)$, abertura (A_s1) e presença (P_s1) localizados sala 1. A fim de definir o comportamento do SAR diante de diferentes situações, foi feita a variação dos valores das entradas, sendo que foram definidos seis estados. Nesse caso, o primeiro é o Stand-by. O segundo é o I2, sendo que está relacionado com a ação de desligar a luz da garagem, além do ar condicionado e luz da sala 1. O terceiro, I3, refere-se a ação de desligar a luz da garagem e ligar a luz da sala 1. O quarto, I4, é resposável pela ação de ligar a luz da garagem e desligar a luz e ar condicionado da sala 1. O quinto, I5, está associado à ação de ligar a luzes da garagem e da sala 1. O último, I6, é responsável pela ativação do alarme. Vale ressaltar que a máquina de Intrusão não gera sinais somente para ativar o alarme, mas também para contribuir com a economia de energia, através da gerência da luz da garagem, também do ar condicionado e luz da sala 1. Outrossim, a Máquina de Estados de intrusão utiliza 3 bits para representar os seus estados.

Por fim, a tabela da Máquina de Estados de Eficiência energética possui três entradas. A primeira entrada é de comando, sendo relacionada ao botão do modo eficiência (Efic) presente no aplicativo mobile. As demais são entradas de sensores, os quais são: o de presença (P_q1) instalado no quarto 1 , além do de luminosidade presente na frente da casa (LDR_fr). Ao realizar a variação dos valores de entrada e a sua implicação no comportamento do SAR, foram definidos cinco estados. Com isso, foram utilizados 3 bits para representá-los. Seguindo o projeto das Máquinas anteriores, o primeiro estado é o Stand-by. O segundo, E2, engloba as ações ligar a luz do jardim e desligar a luz do quarto 1. O terceiro, E3, refere-se a ação de ligar a luz do jardim e ligar a luz do quarto 1. O quarto, E4, é responsável por ordenar ao SAR desligar a luz do jardim e desligar a luz do quarto 1. O quinto, E5, está relacionado à ação de desligar a luz do jardim e ligar a luz do quarto 1. É importante frisar que ao observar os estados supractitados, a presente Máquina só gera sinais para que ocorram ações com o finco de tornar o uso da energia mais eficiente.

\subsection{Projeto e desenvolvimento da Aplicação para o usuário}

Para permitir a interação do usuário com os equipamentos instalados na residência através da internet (IoT), foi desenvolvido um aplicativo mobile através do uso do framework Ionic no software Notepad ++ . Nesse caso, a aplicação desenvolvida é responsável por permitir o controle do sistema de forma remota, sendo que foram implementadas três telas (ver Figura 3). A primeira, concebida como acionamentos, possibilita ao usuário realizar ações de desligar/ligar luzes e ar condicionado da casa, além de ativar/desativar os modos de segurança e economia de energia. A segunda, denominada monitoramento, é responsável por exibir a imagem capturada pela câmera instalada na sala 2, também a temperatura e umidade da casa. A terceira, chamada de Playlist, permite ao usuário do SAR ouvir músicas selecionadas de acordo com sua vontade. Salienta-se que as ações manuais permitidas pelo aplicativo são superiores as ações automáticas oriundas da Máquina de Estados.

Para realizar a comunicação entre o aplicativo e o elemento de controle do SAR (Raspberry P $i$ ) foi utilizada a rede de dados $P u b N u b$. Nesse caso, foram implementados os métodos publish e subscribe para o envio e recebimento de mensagens entre as aplicações. Nesse caso, cada aplicação se inscreve em um canal para realizar as referidas operações, sendo que foram criados canais para todos os comandos presentes no aplicativo (luzes, botões da Playlist), além de um para o monitoramento do sensor de temperatura e umidade. 
Figura 3. Telas desenvolvidas

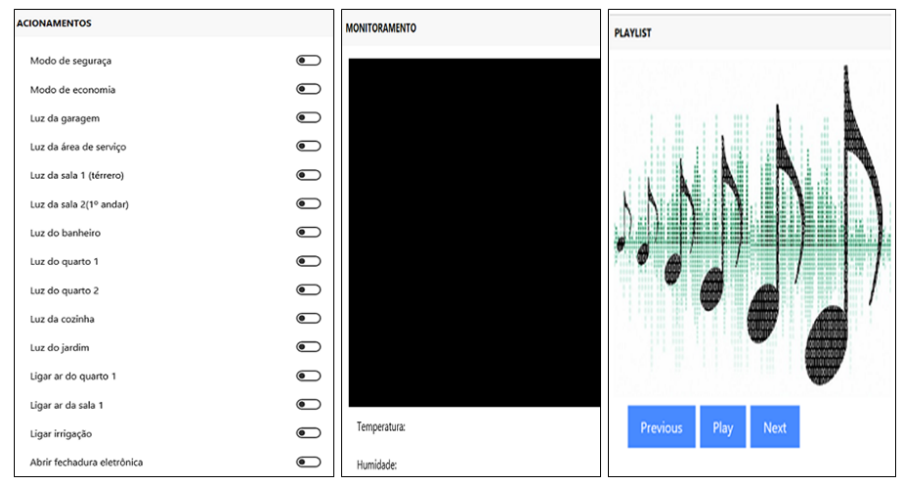

Fonte: Silva Filho e Gertrudes (2019)

\subsection{Instalação do sistema no protótipo residencial}

A instalação do sistema desenvolvido foi complicada devido ao tamanho reduzido do ambiente residencial. Contudo, foram feitos ajustes para que houvesse a acomodação de todos os componentes que fazem parte do SAR. Para a sua instalação foram utilizados os seguintes componentes: 1 Raspberry Pi 3 modelo B, 1 cartão de memória de 8 GB, 1 mouse, 1 caixa de som JBL, 1 teclado, 1 cabo HDMI, fios, resistores, 1 sensor de temperatura e umidade, 4 de presença, 1 de luminosidade (LDR), 1 de gás e fumaça (MQ-2), 1 de abertura e 1 de Radio Frequência $(\mathrm{RF}), 1$ placa (shield) de automação, 1 matriz de contatos (protoboard) para conectar os sensores e outros equipamentos, 1 fonte de 12 Volts e 2 Amperes para alimentar a placa de automação e o Raspberry $P i, 1$ fonte de 5 Volts e 2 Amperes para alimentar os leds, 4 leds verdes straw hat (3.6 Volts), 9 leds brancos straw hat (3.6 Volts), 1 sirene de 12 Volts.

Salienta-se que a placa de automação utilizada possui diversos recursos como: 10 relés, 3 transistores de saída, 8 entradas para contatos secos, entradas analógicas, entre outros. O seu uso foi fundamental para o controle dos leds de forma remota, pois eles são conectados aos relés presentes no shield, além de disponibilizar uma saída transistorizada de 12 Volts para conexão com a sirene.

\section{RESULTADOS E DISCUSSÃO}

Este capítulo tem como objetivo apresentar alguns dos resultados obtidos através da simulação do Sistema de Automação Residencial desenvolvido.

\subsection{Aquisição de dados}

Os primeiros resultados obtidos foram a partir da utilização dos sensores sem fio, sendo os sinais lidos a partir do módulo recepção de $R F$. Pode-se observar na Tabela 5 os valores em decimal obtidos a partir do teste de cada elemento supracitado.

\subsection{Testes no circuito de Incêndio}

Para testar o circuito de incêndio foi feita a ativação do modo de segurança, de modo que a Máquina de Estados não fique somente no estado de Stand-by. Nesse caso, com
Tabela 5. Valores obtidos dos dispsitivos sem fio

\begin{tabular}{|c|c|}
\hline Elemento & Valor em decimal \\
\hline Sensor de presença da garagem & 64252069 \\
\hline Sensor de presença da sala 1 & 62828709 \\
\hline Sensor de presença do quarto 1 & 61564069 \\
\hline Sensor de presença da cozinha & 38791909 \\
\hline Botão desligar & 69475685 \\
\hline Botão A & 126017133 \\
\hline Botão B & 126017141 \\
\hline
\end{tabular}

o uso de um isqueiro, foi feita a liberação do seu gás próximo ao sensor $M Q$-2 e logo em seguida ocorreu o acionamento do alarme e o envio de um e-mail de alerta (visualizar Figura 4), pois não havia a preseça de pessoas na cozinha. Posteriormente, foi feito o mesmo teste só que com a presença de pessoas na cozinha, sendo que somente o alarme foi ativado.

Figura 4. E-mail enviado

\section{Presença de gás detectada!! - Entrada x}

Sandoval Santos Silva Filho<san.ecomp@gmail.com> para mim

Presença de gas na cozinha detectada!!

Fonte: Silva Filho e Gertrudes (2019)

\subsection{Testes no circuito de Intrusão}

A parte do SAR relacionada a intrusão também foi testada, sendo que foram feitos experimentos que pudessem resultar em acionamento do alarme e ações de eficiência energética. O primeiro teste realizado foi uma intrusão na garagem, sendo que o alarme foi imediatamente ativado, já que o modo de segurança estava ativo e o sensor de presença detectou uma invasão no local. Posteriormente, foi feito um teste com o sensor de abertura localizado na sala 1 , sendo que o alarme também foi ativado ao detectar a abertura da porta.

Por fim, foram feitos testes somente com o modo de economia ativado, pois os sensores de presença da garagem e da sala 1 atuam tanto na detecção de intrusão quanto na eficiência energética. Para verificar o funcionamento do recurso implementado, foi feito o acionamento da luz da garagem e do modo de economia. Após um minuto, o SAR desligou a luz da garagem de forma automática, pois o sensor instalado na garagem não detectou a preseça de pessoas durante esse intervalo de tempo.

\subsection{Testes no circuito de Eficiência Energética}

O circuito de Eficiência energética, responsável por reduzir o desperdício da energia elétrica, foi testado em diferentes contextos. Primeiramente, foi feito um teste com as seguintes condições: modo de economia ativado, sem luz na área externa, ausência de pessoas na garagem, sala 1 e quarto 1, luzes do quarto 1 e garagem ligadas, luz da sala 1 e 2 desligadas. Nesse caso, obteve-se como resultado as ações de ativar as luzes do jardim, desligar a luz da 
garagem, além da manuntenção das luzes da sala 1 e quarto 1 desligadas. $O$ estado do sistema antes do teste e o resultado após sua realização podem ser visualizados na Figura 5.

Figura 5. Sistema antes (esquerda) e pós (direita) o primeiro teste
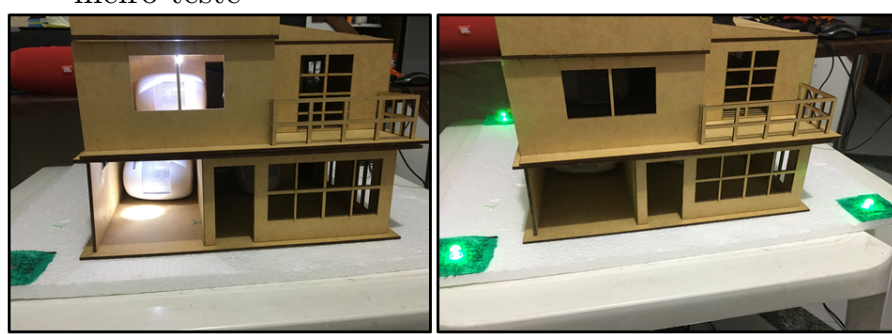

Fonte: Silva Filho e Gertrudes (2019)

No segundo teste foram especificadas as seguintes condições: modo de economia ativado, luz da área externa ligada, luz da garagem ligada, presença de pessoas na garagem, ausência de pessoas na sala 1 e quarto 1 , luzes do quarto 1 e luz da sala 1 ligadas e ar condicionado da sala 1 ligado. Sendo assim, obteve-se como resultado a manutenção da luz da garagem ligada, pois há a presença de pessoas. Também, foram desligados o ar condicionado e as luzes da sala 1 e quarto 1 devido a ausência de pessoas no local. O estado do sistema antes e após o teste ser verificado na Figura 6.

Figura 6. Sistema antes (esquerda) e pós (direita) o segundo teste
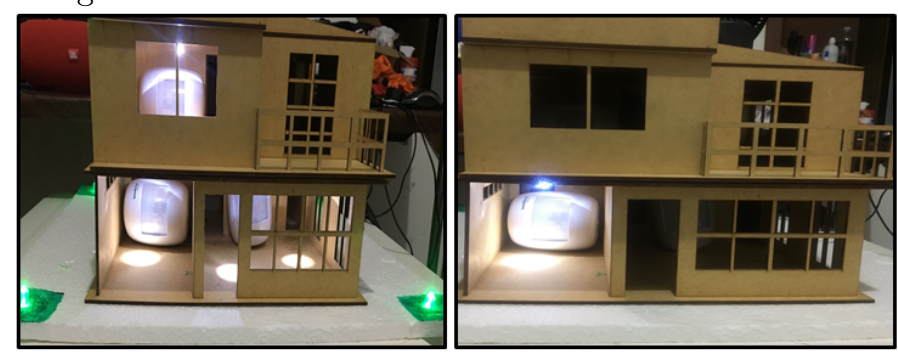

Fonte: Silva Filho e Gertrudes (2019)

\section{CONSIDERAÇÕES FINAIS}

O desenvolvimento do projeto permitiu realizar uma pesquisa sobre todos os aspectos necessários para a construção de um Sistema de Automação Residencial, além de verificar que o uso do Raspberry Pi em Sistemas de Automação Residencial é possível, pois ele oferece diversos recursos que são essenciais para implementar as funcionalidades desejadas pelo usuário.

O projeto e a implementação da Máquina de Estados demandou atenção, pois implica diretamente no funcionamento do sistema. Ademais, possibilitou a construção de uma lógica de controle com funcionamento correto para um sistema específico, além de permitir a coexistência dos requisitos de segurança, comodidade e eficiência energética em um mesmo Sistema de Automação Residencial.

O desenvolvimento do aplicativo mobile foi facilitado pelo uso do framework Ionic, o qual disponibiliza diversos componentes gráficos e ainda facilita a exportação do aplicativo para a plataforma Android. Outrossim, o uso da rede $P u b N u b$ foi fundamental para realizar a comunicação entre o Raspberry Pi e o aplicativo, sendo feita através do envio de mensagens.

Como sugestão para trabalhos futuros pode ser feita a instalação do sistema numa casa real, além da ampliação das funcionalidades do sistema desenvolvido. Nesse caso, pode ser implementada a integração entre o sensor de temperatura e humidade com um sistema de irrigação, de modo a acionar a irrigação automaticamente caso a temperatura atinja um determinado valor. Por fim, pode ser projetado um processo de mitigação do vazamento do gás através da contrução de uma vávula com acionamento pneumático, sendo acoplada ao registro do gás de cozinha.

\section{AGRADECIMENTOS}

Agradecemos ao Programa de Pós Graduação em Computação Aplicada da Universidade Estadual de Feira de Santana pelo suporte ao trabalho desenvolvido.

\section{REFERENCIAS}

Azni, M.N., e A. H. Zianal e F. A. Mohammed e N. N. M. Daud e R. Vejasegaran e N. W. Basharudin e M. Jusoh e K. Azir, L.V., and Kan, P.L.E. (2016). Home automation system with android application. In Proc. 3rd Int. Conf. Electronic Design (ICED), 299-303. doi: 10.1109/ICED.2016.7804656.

Batistelo, R. (2014). Automação residencial utilizando raspberry pi e android. Trabalho de Conclusão de Curso apresentado ao Curso de Sistemas de Informação da Universidade do Oeste de Santa Catarina.

Castro, Javier e Psota, J. (2009). The specification, design, and implementation of a home automation system. The American Journal of systems.

D. Sunehra, M.Y. (2015). Implementation of interactive home automation systems based on email and Bluetooth technologies. In Proc. Int. Conf. Information Processing (ICIP), 458-463. doi:10.1109/INFOP.2015.7489426.

O. Bingol, K.T. (2014). Web-based smart home automation:plc-controlled implementation. Acta Polytechnica Hungaria: Journal of Applied Science. Volume 11, Issue No. 3.

S. Folea e D. Bordencea, C.H.e.H.V. (2012). Smart home automation system using wi-fi low power devices. In Proc. IEEE Int. Conf. Automation, Quality and Testing Robotics, 569-574. doi:10.1109/AQTR.2012.6237775. 